\title{
BMJ Open Evaluating the motivation of Red Cross Health volunteers in the COVID-19 pandemic: a mixed-methods study protocol
}

\author{
Leonardo W Heyerdahl, ${ }^{1}$ Muriel Vray, ${ }^{2}$ Vincent Leger, ${ }^{3}$ Lénaig Le Fouler, ${ }^{4}$ \\ Julien Antouly, ${ }^{3}$ Virginie Troit, ${ }^{3}$ Tamara Giles-Vernick (D) ${ }^{1}$
}

To cite: Heyerdahl LW, Vray M, Leger $\mathrm{V}$, et al. Evaluating the motivation of Red Cross Health volunteers in the COVID-19 pandemic: a mixed-methods study protocol. BMJ Open 2021;11:e042579. doi:10.1136/ bmjopen-2020-042579

- Prepublication history for this paper is available online. To view these files, please visit the journal online (http://dx.doi. org/10.1136/bmjopen-2020042579).

Received 08 July 2020 Revised 03 December 2020 Accepted 10 January 2021

Check for updates

(C) Author(s) (or their employer(s)) 2021. Re-use permitted under CC BY-NC. No commercial re-use. See rights and permissions. Published by BMJ.

${ }^{1}$ Anthropology \& Ecology of Disease Emergence Unit/Global Health, Institut Pasteur, Paris, France

${ }^{2}$ Emerging Diseases

Epidemiology Unit/Global Health, Institut Pasteur, Paris, France

${ }^{3}$ Fondation de la Croix-Rouge francaise, Croix-Rouge francaise, Paris, France

${ }^{4}$ Data Management Core Facility, Institut Pasteur, Paris, France

Correspondence to

Dr Tamara Giles-Vernick;

tamara.giles-vernick@pasteur.fr

\section{ABSTRACT}

Introduction Voluntary organisations provide essential support to vulnerable populations and front-line health responders to the COVID-19 pandemic. The French Red Cross (FRC) is prominent among organisations offering health and support services in the current crisis. Comprised primarily of lay volunteers and some trained health workers, FRC volunteers in the Paris (France) region have faced challenges in adapting to pandemic conditions, working with sick and vulnerable populations, managing limited resources and coping with high demand for their services. Existing studies of volunteers focus on individual, social and organisational determinants of motivation, but attend less to contextual ones. Public health incertitude about the COVID-19 pandemic is an important feature of this pandemic. Whether and how uncertainty interacts with volunteer understandings and experiences of their work and organisational relations to contribute to Red Cross worker motivation is the focus of this investigation. Methods and analysis This mixed-methods study will investigate volunteer motivation using ethnographic methods and social network listening. Semi-structured interviews and observations will illuminate FRC volunteer work relations, experiences and concerns during the pandemic. A questionnaire targeting a sample of Paris region volunteers will allow quantification of motivation. These findings will iteratively shape and be influenced by a social media (Twitter) analysis of biomedical and public health uncertainties and debates around COVID-19. These tweets provide insight into a French lay public's interpretations of these debates. We evaluate whether and how socio-political conditions and discourses concerning COVID-19 interact with volunteer experiences, working conditions and organisational relations to influence volunteer motivation. Data collection began on 15 June 2020 and will continue until 15 April 2021.

Ethics and dissemination The protocol has received ethical approval from the Institut Pasteur Institutional Review Board (no 2020-03). We will disseminate findings through peer-reviewed articles, conference presentations and recommendations to the FRC.

\section{INTRODUCTION}

The French Red Cross (FRC) is a nongovernmental organisation providing critical
Strengths and limitations of this study

- Qualitative interviews and non-participant observation capture activities and perceptions of volunteers during the COVID-19 pandemic.

- Use of social media (Twitter) traces broad public understandings of biomedical and public health debates around COVID-19.

- Putting qualitative, quantitative and social media listening into dialogue can reveal whether and how volunteer motivations are shaped by lay interpretations of public health debates around COVID-19.

- Neither social media nor questionnaire will yield a representative sample of volunteers or the broad public in France.

support for France's health system in the current COVID-19 crisis, particularly in the Paris region where SARS-CoV-2 transmission was very high between March and May 2020. The FRC is just one entity within the International Red Cross Red Crescent Movement, comprised of national societies of the Red Cross and the Red Crescent, the International Committee of the Red Cross (ICRC) and the International Federation of the Red Cross (IFRC). Among the ranks of FRC's estimated 42814 volunteers in the Paris region are rescue workers, physicians, nurses, nursing assistants and technicians performing emergency and first aid response and healthcare. Many volunteers, however, are lay people undertaking social assistance that can shape the health and well-being of recipients. This assistance includes training, delivering food, clothing and other resources to vulnerable populations, and providing services for children. To sustain the continuity of FRC activities in supporting these populations and France's national COVID-19 response, understanding and safeguarding volunteer motivation during a pandemic is 
critically important. This question of motivation is pertinent to other countries with Red Cross/Red Crescent or other voluntary organisations providing essential support for pandemic response.

This study emerges from multiple, interacting challenges that pivot around sustaining volunteer activities during a public health emergency. The FRC volunteer population is heterogeneous, with diverse experiences, training, expectations and tasks to fulfil during this pandemic, although the ICRC provides guidance during epidemics. ${ }^{1}$ Most volunteers began voluntary work before the pandemic, but changes in FRC operations and sanitary and social needs may affect their motivation, which we preliminarily frame as willingness to continue volunteer activities during the COVID-19 pandemic.

For decades, behavioural scientists and psychologists have evaluated volunteer engagement in several contexts, identifying individual-level and organisationallevel drivers that shape 'motivation'. Their definitions of volunteer 'motivation' vary substantially; as Cnaan and Goldberg-Glen observed, 'to a large extent, it is subconsciously constructed'. ${ }^{23}$ Studies have identified multiple factors shaping volunteer motivations: a volunteer's sense of self-worth in volunteering; the expansion and strengthening of social relations; the acquisition of career-related experience; adherence to the organisation's goals, for instance. ${ }^{4-9}$ One qualitative interpretive meta-synthesis evaluated five qualitative studies of crisis counselling volunteers and found six cross-cutting themes shaping motivation. ${ }^{10}$ They identified a desire to make an 'external difference'; 'volunteer existentialism', which referred to pursuing an activity to gain understanding of their own lives and to achieve connectedness with other people; 'lived experience', pertaining to experiences of suffering and meanings that volunteers attributed to these experiences through volunteering; achievement of a sense of personal fulfilment through volunteer work; and finally, 'lack of direction' and 'lack of support' from superiors within the organisation, which reduced motivation. ${ }^{10}$

Such factors may also influence FRC volunteers, but the extraordinary conditions under which they are working may also shape their engagement. The COVID-19 pandemic has affected France substantially, and there exists considerable biomedical and public health incertitude, or incomplete knowledge. ${ }^{11}$ 'Incomplete knowledge' has preoccupied anthropologists for decades, including during epidemics. ${ }^{12-15}$ Andy Stirling's conceptualisation of incertitude and lay public engagement with science-based decisions is especially useful here. Stirling proposed three types of incertitude: uncertainty, ambiguity and ignorance. Uncertainty pertains to a public's knowledge of the possible outcomes of an event, but not the likelihood of those outcomes, whereas ambiguity results from their characterisation of a problem in divergent ways, proposing multiple possible outcomes. Although ignorance tends to have pejorative connotations, Stirling employs it to indicate when a lay public does not know the possible or probable outcomes of an event. Seen through the optic of Stirling's categories, the COVID-19 pandemic has catalysed public interpretations of biomedical and public health debates about epidemic origins, transmission, symptoms, risk factors, protective measures and possible treatments, producing shared uncertainties, ambiguities and ignorance. For instance, although virologists have debated animal origins of the SARS-CoV-2 virus ${ }^{16-18}$ and strenuously denied the possibility that it was a laboratory creation, certain social groups have advanced ambiguous (alternative) explanations for its emergence. These ambiguous explanations can undermine confidence in both scientists and authorities, their measures to control transmission, and possibly measures of prevention, such as vaccines. ${ }^{19}$ Epidemiologists have measured SARS-CoV-2 infection attack rates ${ }^{20}$; a lay public may recognise the possibility of infection but may remain uncertain about its probability, and about how everyday actions may facilitate or prevent transmission. Public incertitude about COVID-19 is an important feature of this pandemic, so it is worth exploring whether and how it may affect volunteer motivation over the study duration.

Contributions to the volunteer motivation literature offer some guidance here, particularly those tackling how 'crisis' volunteers respond to and are affected by high-risk situations, including mental health crisis centres, armed conflicts, refugee centres and epidemics. ${ }^{21-26}$ Anthropological investigations of volunteers in health emergencies are relatively rare, but can illuminate how they make sense of the pandemic, their work and the socio-political settings and organisation hierarchies within which they operate. ${ }^{27}$ One study demonstrated the importance of exploring motivation through an anthropological lens, showing how changing socio-political contexts influenced volunteer engagement during Germany's immigration crisis. ${ }^{28}$ Volunteers initially borrowed from broader public discourses to attribute meaning to their efforts with refugees, but as the socio-political relations with refugees changed, they altered the 'meaningfulness' of their work by drawing on new social discourses about migrants. We appreciatively draw from this approach. During the current COVID-19 pandemic, volunteer 'motivation' may not only be influenced by relations between volunteers and recipients of their work and the FRC organisational structures; broader socio-political interpretations of biomedical and public health debates may also affect their engagement.

The study is conducted by social scientists at the Institut Pasteur in collaboration with the Fondation Croix-Rouge française (FCRF), a foundation that is independent from the FRC and is dedicated to social and humanitarian action.

\section{Objective}

The primary objective of the study is to identify drivers of motivation (and demotivation) for FRC volunteers in the current pandemic, determining whether and 
Table 1 Data collection tools and timing

\begin{tabular}{|c|c|c|c|}
\hline Method & Timing & Population & Data collected \\
\hline Questionnaire (online) & $\begin{array}{l}3 \text { rounds: month } 1 \text {, month } 5 \text {, } \\
\text { month } 10\end{array}$ & $\begin{array}{l}\text { FRC volunteers in } \\
\text { lle de France }\end{array}$ & $\begin{array}{l}\text { Volunteer activities, training, media } \\
\text { sources consulted, motivation }\end{array}$ \\
\hline $\begin{array}{l}\text { Social media and media listening } \\
\text { (Twitter, including media links and } \\
\text { opinion pieces in widely circulating } \\
\text { newspapers) }\end{array}$ & $\begin{array}{l}\text { Continuous, from June 15, } \\
2020 \text { through } 15 \text { April } 2021\end{array}$ & $\begin{array}{l}\text { Social media and } \\
\text { media users in } \\
\text { France }\end{array}$ & $\begin{array}{l}\text { Public opinion concerning debates } \\
\text { and uncertainties around COVID-19 } \\
\text { prevention, diagnosis, research }\end{array}$ \\
\hline Observation & $\begin{array}{l}\text { Continuous but contingent } \\
\text { on national lockdown } \\
\text { regulations and volunteer } \\
\text { availability }\end{array}$ & $\begin{array}{l}\text { FRC volunteers in } \\
\text { lle de France }\end{array}$ & $\begin{array}{l}\text { Volunteer activities, hidden } \\
\text { motivations concerning volunteer work }\end{array}$ \\
\hline
\end{tabular}

how socio-political interpretations of biomedical and public health uncertainties and debates affect volunteer motivation.

\section{Study hypothesis}

We hypothesise that volunteer motivation not only results from individual preparation and training, material and other resources, and working conditions, but also the influence of scientific and public health debates on public incertitude about COVID-19, its transmission, control, potential treatments and consequences.

\section{METHODS AND ANALYSIS}

We will carry out a descriptive mixed-methods ${ }^{29} 30$ study with repeated measures to investigate FRC volunteers and social media users in France (table 1). Qualitative ethnographic tools (semi-structured interviews, nonparticipant observation) provide emic (interior) insight into volunteer understandings of activities, accomplishments and reasons for serving as volunteers; their emotional responses to the challenges of volunteer work before and during the COVID-19 pandemic; anxieties experienced while carrying out activities during the pandemic; how they define 'motivation' and their willingness to continue volunteer work. A quantitative survey will capture changing volunteer motivations at months 1,5 and 10 of the study. Simultaneously, we will continuously collect data from the microblogging and social media site, Twitter, supplemented by daily print media to track French public interpretations of scientific and public health debates around COVID-19. All data collection will be conducted by researchers with doctoral training and many years of qualitative and quantitative field research experience. Data collection began on 15 June 2020 and will continue until 15 April 2021.

\section{Sample selection}

The following inclusion and exclusion criteria pertain to individual participants in the rapid questionnaire, interview and non-participant observation.

\section{Inclusion criteria}

- FRC volunteers in Ile de France (the city of Paris and surrounding region, total population 12.2 million).

- Adult volunteers (aged more than 18 years old).

- Acceptance of participation in the study and a team researcher recording or note taking during the interview or observation.

\section{Exclusion criteria}

- Volunteers who suffer from any type of illness that could affect their capacity to provide informed consent or to participate in the study.

The FRC has extracted from its volunteer database a list of 26\% of its total volunteers (11 388) in the eight administrative departments of Ile de France. This list was compiled randomly, but respected overall proportions by department, age and gender. From this list, we will send the questionnaire to those with a listed FRC email. Those included in the questionnaire will receive the questionnaire in months 1,5 and 10 of the study. The first round provides baseline information following an 8-week lockdown in France; the second coincides with a widely predicted second COVID-19 transmission wave and confinement; the third will overlap with implementation of additional measures to prevent COVID-19, including vaccination.

We will select participants for qualitative interviews from this same list and if necessary, through convenience sampling (recommendations of interviewed volunteers) proportionate to age, gender, administrative departments and FRC activities during and in support of COVID-19 response. Hence, some subjects may participate in both the questionnaire and interviews, but because questionnaire responses are anonymised, we will not know if they have done so. Up to one-quarter of all interview participants may participate in a second interview, so that we can evaluate changing motivations, perceptions and experiences over the study period.

Participants in non-participant observations will be selected in accord with local units and the consent of 
volunteers. We will not know whether questionnaire respondents are among the volunteers observed.

\section{Data collection tools}

\section{Questionnaire}

The short questionnaire will be in French. We will administer this rapid questionnaire three times to track changing volunteer motivation in months 1,5 and 10 of the study. The questionnaire has been reviewed for comprehension by FRC administrators and the independent FRCf employees.

The questionnaire consists of four sections.

Section 1: Limited personal information (age, gender, education).

Section 2: Type of volunteer work conducted for the FRC; prior volunteer or professional work experience during epidemics; volunteer's opinion about preparation and material support to conduct work.

Section 3: Media consulted by volunteers; means of communications with the FRC hierarchy and co-workers.

Section 4: Volunteer feelings about conducting work during the pandemic; whether they are 'motivated' to continue this work. Here participants are invited to explain at greater length their responses. These responses will inform key terms that we will investigate in our social network listening.

Quantifiable questions are structured with Likert scale uneven-point responses.

\section{Qualitative tools}

\section{Semi-structured interviews}

Following the first questionnaire and for the remainder of the study, we will continuously conduct 60 individual semi-structured interviews (or until saturation) with FRC volunteers in Ile de France. Participants will be selected from our sample to reflect the proportion of gender, age, departmental distribution and activities of volunteers (divided evenly between those working on 'social action' or 'emergency response', as described on the public FRC website). If we encounter difficulties recruiting volunteers through their FRC email accounts, we will also conduct convenience sampling to ensure that our interviews reach saturation.

Interviews, consisting of nine open-ended questions, will explore volunteer perceptions and experiences of new responsibilities, practices or policies implemented during the pandemic that affect their activities; different concerns that influence their volunteer work, and how they define and evaluate their 'motivation' to continue this work. The interview guide was reviewed for comprehension and revised by one FRC volunteer and three FCRF employees, who also are FRC volunteers. Interviews will initially be conducted remotely via telephone, Zoom or Skype, depending on participant preference. Should epidemic conditions improve considerably in Ile de France, we will attempt to conduct interviews in person.

\section{Non-participant observation}

We will conduct non-participant observations of volunteer activities in Ile de France to document volunteer working conditions and their interactions with one another, hierarchical supervisors and recipients of volunteer support. These observations will be organised through FRC administrators and with authorisation of local units and consent of volunteers. We will observe and take detailed notes on specific activities, volunteer interactions with one another and with recipients of their assistance. This method will over time facilitate relations of confidence with volunteers and offer deeper insight into volunteer motivations.

\section{Twitter and media listening}

Social networks provide a common data source for public understandings of epidemics, ${ }^{31-36}$ and associated public health intervention. ${ }^{37-39}$ We will use Tweets from France to track public debates around scientific and public health uncertainties concerning SARS-CoV-2 transmission, affected groups, long-term effects; non-pharmaceutical protective measures; developing or proposed prevention, control and treatment measures. Because Twitter does not represent broad public opinion, we compensate for potential biases by following all links to articles, editorials and letters in newspapers, journals and user-generated websites. We also consult editorials and letters in newspapers with wide circulation. We will collect media-derived data daily for the entire project duration to track rapidly changing information about COVID-19 and reactions to it.

Twitter/media listening and our quantitative and qualitative methods are iterative: results from our analysis of key debates in our Twitter/media listening will inform questions in questionnaires and interviews; concerns or uncertainties defined by participants, which may affect their motivations to pursue volunteer activities, provide key terms to track on Twitter. These uncertainties and debates provide insight into socio-political conditions and discourses that volunteers encounter. Even if individual volunteer participants in our study do not follow Twitter, key terms and debates over public health measures can nonetheless provide an indicator of these conditions. ${ }^{40}$ We use Twitter and newspaper editorials and letters as a proxy for these social debates around scientific and public health uncertainties, enabling us to ask better, more timely questions to volunteers to determine if they are following these debates, how they interpret and act on them, and whether they influence volunteer motivations.

Using the $\mathrm{R}$ programming language ${ }^{41}$ and the rtweet library, ${ }^{42}$ we will submit queries to the Twitter Application Interface for all relevant tweets. Our search strategy will be modular, adapting to epidemic events and scientific and public health debates. A standard keyword query using 'coronavirus OR COVID-19' will be run daily, requesting all corresponding tweets in the French language. Only organic tweets (not retweets) originating in France will be collected. Additional queries will address specific concerns emerging from interviews. For instance, the query 'masks' will collect tweets on debates about uses, utility and availability of masks. 


\section{Sample size calculation}

We will evaluate 'motivation' of volunteers, but are not seeking to obtain a statistically representative sample of the 42814 volunteers in Ile de France. Our sampling strategy is stratified by age, gender and departmental distribution of the volunteer population, and sample size calculations for the questionnaire are designed to obtain a response from approximately $4 \%$ of all volunteers. Although all volunteers should receive an FRC email account, the FRC cannot continuously update its database. Out of the 11388 randomly extracted names that convened to eligibility criteria, 6528 included a listed email account. We will therefore send the questionnaire to these 6528 volunteers in months 1,5 and 10 of the study, anticipating that a third will respond at least once. Our decision not to seek a statistically representative sample of volunteers is several. First, access to volunteers through FRC emails will not be reliable, particularly because it remains difficult for the organisation to continuously update its database. Second, our knowledge of other survey-based studies during this pandemic period reveals unusually low response rates, perhaps of fatigue and stress experienced during this time.

Interview sample sizes will either reach 60 total interviews, or until saturation-that is, when interviewers collect no new evidence from the interviews. Participants will be randomly selected, but equally divided between volunteers in 'social actions' and those in 'emergency response'.

We will conduct up to 15 days of non-participant observations.

The number of tweets collected daily may vary from a few thousand to above 100000 , depending on the epidemiology of COVID-19 and ongoing debates.

\section{Data analysis plan}

Quantitative analysis of questionnaire data

Questionnaire data will be evaluated in the software Stata. ${ }^{43}$ We will produce descriptive statistics of participants, their sense of preparedness and support to carry out their work, their concerns and 'motivation' to continue volunteer work. Quantitative measures of motivation will rely on frequencies of scales of motivation and will analyse distribution by age, gender and activities.

\section{Interview analyses}

We will employ thematic and semantic analysis of interviews. Interview recordings or notes will be transcribed in Word. We will use the qualitative data software NVivo (Release 1.2).${ }^{44}$ Anthropologists conducting the study will conduct a first read of the interviews to identify repeated coding categories. Two anthropologists will conduct initial coding of all qualitative data, comparing results and resolving differently interpreted data segments.

A second coding will identify key categories and develop theories explaining practices, emotional responses to volunteer work during the COVID-19 pandemic and conditions, relations and uncertainties that shape these theories about motivation. We will attend to educational, generational and gender influences that might shape these categories and theories. Two rounds of data coding conducted by two experienced researchers, as well as frequent meetings and memos to address emerging themes will ensure the validity of our qualitative analyses.

\section{Twitter and media listening analysis}

Every 2 weeks, we will analyse tweets to track debates in France concerning transmission, protection, prevention, possible treatments and the long-term consequences of COVID-19.

The quantitative analysis of tweets will provide an overview of COVID-19 debates by producing top hashtag tables and word and hashtag clouds. ${ }^{45}$

The qualitative analysis will conduct thematic, lexical and semantic analysis of the corpus. When a particular debate emerges (determined by emerging tags or keywords in tweets, an increased number of tweets collected that include these terms, by references to these debates in interviews), we will collect a random sample of messages accumulated during the previous 2 weeks. Sample size will be 1400 messages-sufficiently large to obtain saturation, but small enough to manage qualitative analysis.

Deductive and inductive coding of the corpus will be carried out using NVivo software. We will produce a coding framework that reflects broad categories of interest emerging from interviews, particularly those relating to volunteer concerns. During the first phase, one team researcher will code the corpus using this frame. The second phase of coding will be inductive, noting emergent themes from the categorised corpus. Team anthropologists will discuss and validate these themes. When tweets include links to press articles or videos, we will consult these sources to understand better message meanings or to gain insight into disparities between messages and sources external to Twitter. These disparities and contextualisation will be integrated into our database. Images and emoticons will not be accounted for, because of the volume of tweets analysed.

We will triangulate these results with analyses of interviews, observations and questionnaires, to identify linkages between volunteer challenges and anxieties and public interpretations and debates on Twitter about COVID-19. Qualitative evidence from all methods will be integrated into NVivo software and coded using parallel coding trees. Related sets of coded data will be synthesised and compared at specific junctures in the study to produce analyses of the drivers of changing volunteer motivations, perceptions and practices.

\section{Patient and public involvement}

Multiple FRC volunteers contributed to the development of our data collection tools before the study. We have not involved patients in developing the protocol. 


\section{ETHICS AND DISSEMINATION}

The protocol has received ethical approval from the Institut Pasteur Institutional Review Board (IRB no 202003). The Ethics Committee of the Croix-Rouge française also reviewed the protocol.

All participants will receive an information notice describing the objectives and conduct of the questionnaire, qualitative interviews, and focus group discussions. Participation in these data collection tools will constitute informed consent.

To protect study participant identities, all data will be de-identified, aggregated and deposited at Institut Pasteur. Our analysis of Twitter data, using anthropological coding procedures, will aggregate and paraphrase these data to protect fully the identities of those producing tweets.

We will disseminate our findings through periodic recommendations to the FRC, peer-reviewed articles and conference presentations.

\section{DATA STATEMENT}

Because of IRB restrictions, we are unable to make data publicly available.

Contributors LWH and TG-V developed the protocol, with significant contributions from MV, LLF, JA, VL and VT. LWH and TG-V drafted the manuscript. MV, LLF, JA and VL contributed to revisions of the manuscript. All authors approved the final manuscript.

Funding This work was supported by the Institut Pasteur and by the Inception Programme (ANR 16-CONV-0005).

Competing interests None declared.

Patient and public involvement Patients and/or the public were involved in the design, or conduct, or reporting, or dissemination plans of this research. Refer to the Methods section for further details.

Patient consent for publication Not required.

Provenance and peer review Not commissioned; externally peer reviewed.

Open access This is an open access article distributed in accordance with the Creative Commons Attribution Non Commercial (CC BY-NC 4.0) license, which permits others to distribute, remix, adapt, build upon this work non-commercially, and license their derivative works on different terms, provided the original work is properly cited, appropriate credit is given, any changes made indicated, and the use is non-commercial. See: http://creativecommons.org/licenses/by-nc/4.0/.

ORCID iD

Tamara Giles-Vernick http://orcid.org/0000-0003-2873-8544

\section{REFERENCES}

1 International Federation of Red Cross and Red Crescent. Epidemic control for volunteers: a training manual. Geneva, 2008.

2 Cnaan RA, Goldberg-Glen RS. Measuring motivation to volunteer in human services. J Appl Behav Sci 1991;27:269-84.

3 Ryan RM, Deci EL, Intrinsic DEL. Intrinsic and extrinsic motivations: classic definitions and new directions. Contemp Educ Psychol 2000;25:54-67.

4 Clary EG, Snyder M. The motivations to volunteer: theoretical and practical considerations. Curr Dir Psychol Sci 1999;8:156-9.

5 Bang $\mathrm{H}$, Ross SD. Volunteer motivation and satisfaction. J Venue Event Manag 2009;1:61-77.

6 Clary EG, Snyder M, Ridge RD, et al. Understanding and assessing the motivations of volunteers: a functional approach. J Pers Soc Psychol 1998;74:1516-30.
7 Yanay GV, Yanay N. The decline of motivation?: From commitment to dropping out of volunteering. Nonprofit Manag Leadersh 2008; 19:65-78.

8 McCormick L, Donohue R. Antecedents of affective and normative commitment of organisational volunteers. Int $\mathrm{J}$ Hum Resour Manag 2019;30:2581-604.

9 Doidge M, Sandri E. 'Friends that last a lifetime': the importance of emotions amongst volunteers working with refugees in Calais. $\mathrm{Br} \mathrm{J}$ Sociol 2019;70:463-80.

10 Aguirre RTP, Bolton KMW. Why do they do it? a qualitative interpretive meta-synthesis of crisis volunteers' motivations. Soc Work Res 2013;37:327-38.

11 Stirling A. Risk, precaution and science: towards a more constructive policy debate. talking point on the precautionary principle. EMBO Rep 2007;8:309-15.

12 Last M. The importance of knowing about not knowing. Soc Sci Med B 1981;15:387-92.

13 Littlewood R. On knowing and not knowing in the anthropology of medicine. Left Coast Press, 2007

14 High C, Kelly A, Mair J. The anthropology of ignorance: an ethnographic approach. Springer, 2012.

15 Kelly AH, Lezaun J, Löwy I, et al. Uncertainty in times of medical emergency: knowledge gaps and structural ignorance during the Brazilian Zika crisis. Soc Sci Med 2020;246:112787.

16 Wu D, Wu T, Liu Q, et al. The SARS-CoV-2 outbreak: what we know. Int J Infect Dis 2020;94:44-8.

17 Andersen KG, Rambaut A, Lipkin WI, et al. The proximal origin of SARS-CoV-2. Nat Med 2020;26:450-2.

18 Zhang T, Wu Q, Zhang Z. Probable Pangolin origin of SARS-CoV-2 associated with the COVID-19 outbreak. Curr Biol 2020;30:1578.

19 Seyd B. Coronavirus: trust in political figures is at a low just as they need citizens to act on their advice. Conversat, 2020. Available: https://theconversation.com/coronavirus-trust-in-political-figures-isat-a-low-just-as-they-need-citizens-to-act-on-their-advice-133284 [Accessed 11 Mar 2020].

20 Fontanet A, Tondeur L, Madec Y, et al. Cluster of COVID-19 in northern France: a retrospective closed cohort study. medRxiv 2020.

21 The Volunteering in conflicts and emergencies initiative (ViCE) Hub. Available: http://www.rcrcvice.org/our-initiative/ [Accessed 12 May 2020].

22 Kpanake L, Dounamou T, Sorum PC, et al. What motivates individuals to volunteer in Ebola epidemic response? A structural approach in guinea. Hum Resour Health 2019;17:81.

23 McNamee LG, Peterson BL. High-Stakes volunteer commitment: a qualitative analysis. Nonprofit Volunt Sect Q 2016;45:275-94.

24 Vattø IE, Lien L, DeMarinis V. Caught between expectations and the practice field: experiences of this dilemma among volunteers operating a diaconal crisis line in Norway. Cris J Cris Interv Suicide Prev 2019;40:340-6.

25 Sundram F, Corattur T, Dong C, et al. Motivations, expectations and experiences in being a mental health helplines volunteer. Int $J$ Environ Res Public Health 2018;15:2123.

26 Sifaki-Pistolla D, Chatzea V-E, Vlachaki S-A, et al. Who is going to rescue the rescuers? Post-traumatic stress disorder among rescue workers operating in Greece during the European refugee crisis. Soc Psychiatry Psychiatr Epidemiol 2017;52:45-54.

27 Stellmach D, Beshar I, Bedford J, et al. Anthropology in public health emergencies: what is anthropology good for? BMJ Glob Health 2018;3:e000534.

28 Florian M, Costas J, Kärreman D. Struggling with meaningfulness when context shifts: volunteer work in a German refugee shelter. J Manag Stud 2019;56:589-616.

29 Pelto PJ. What is so new about mixed methods? Qual Health Res 2015;25:734-45.

30 Leech NL, Onwuegbuzie AJ. Guidelines for conducting and reporting mixed research in the field of counseling and beyond. J Couns Develop 2010;88:61-9.

31 Müller MM, Salathé M. Crowdbreaks: tracking health trends using public social media data and crowdsourcing. Front Public Health 2019;7:81.

32 Rudra K, Sharma A, Ganguly N, et al. Classifying and summarizing information from microblogs during epidemics. Inf Syst Front 2018;20:933-48.

33 Miller M, Banerjee T, Muppalla R, et al. What are people tweeting about Zika? An exploratory study concerning its symptoms, treatment, transmission, and prevention. JMIR Public Health Surveill 2017;3:e38.

34 Sharma M, Yadav K, Yadav N, et al. Zika virus pandemic-analysis of Facebook as a social media health information platform. Am J Infect Control 2017;45:301-2. 
35 Morin C, Bost I, Mercier A, et al. Information circulation in times of Ebola: Twitter and the sexual transmission of Ebola by survivors. PLoS Curr 2018;10. doi:10.1371/currents. outbreaks.4e35a9446b89c1b46f8308099840d48f. [Epub ahead of print: 28 Aug 2018].

36 Roy M, Moreau N, Rousseau C, et al. Ebola and localized blame on social media: analysis of Twitter and Facebook conversations during the 2014-2015 Ebola epidemic. Cult Med Psychiatry 2020;44:56-79.

37 Kata A. Anti-vaccine activists, Web 2.0, and the postmodern paradigm--an overview of tactics and tropes used online by the antivaccination movement. Vaccine 2012;30:3778-89.

38 Moran MB, Lucas M, Everhart K, et al. What makes anti-vaccine websites persuasive? A content analysis of techniques used by antivaccine websites to engender anti-vaccine sentiment. J Commun Healthc 2016;9:151-63.
39 Shapiro GK, Surian D, Dunn AG, et al. Comparing human papillomavirus vaccine concerns on Twitter: a cross-sectional study of users in Australia, Canada and the UK. BMJ Open 2017:7:e016869.

40 Aiello AE, Renson A, Zivich PN. Social Media- and Internet-based disease surveillance for public health. Annu Rev Public Health 2020;41:1-18.

41 Team RC. $R$ version 3.5. 1 (feather spray): a language and environment for statistical computing. Austria: R Found Stat Comput Vienna, 2018. https//www r-project org

42 Kearney MW. rtweet: collecting and analyzing Twitter data. J Open Source Softw 1829;2019:4.

43 StataCorp LLC. Stata statistical software: release 16. College Station, TX, 2019.

44 QSR International. NVivo qualitative data analysis software, 1999.

45 Fellows I. wordcloud: word clouds. R package version 2.6, 2018. 